P0176

\title{
EVALUATION BETWEEN ENERGY EFFICIENCY, ECOLOGICAL IMPACT AND THE COMPLIANCE OF REGULATIONS OF ROAD LIGHTING
}

\author{
Annika Jägerbrand
}

DOI 10.25039/x46.2019.PO176

from

CIE x046:2019

Proceedings

of the

29th CIE SESSION

Washington D.C., USA, June 14 - 22, 2019

(DOI 10.25039/x46.2019)

The paper has been presented at the 29th CIE Session, Washington D.C., USA, June 14-22, 2019. It has not been peer-reviewed by CIE.

(C) CIE 2019

All rights reserved. Unless otherwise specified, no part of this publication may be reproduced or utilized in any form or by any means, electronic or mechanical, including photocopying and microfilm, without permission in writing from CIE Central Bureau at the address below. Any mention of organizations or products does not imply endorsement by the CIE.

This paper is made available open access for individual use. However, in all other cases all rights are reserved unless explicit permission is sought from and given by the CIE.

CIE Central Bureau

Babenbergerstrasse 9

A-1010 Vienna

Austria

Tel.: +4317143187

e-mail: ciecb@cie.co.at

www.cie.co.at 


\title{
EVALUATION BETWEEN ENERGY EFFICIENCY, ECOLOGICAL IMPACT AND THE COMPLIANCE OF REGULATIONS OF ROAD LIGHTING
}

\author{
Jägerbrand, A.K. ${ }^{1}$ \\ ${ }^{1}$ Department of Construction Engineering and Lighting Science, School of Engineering, Jönköping \\ University, P.O. Box 1026, SE-551 11 Jönköping, SWEDEN
}

annika.jagerbrand@ju.se

DOI 10.25039/x46.2019.PO176

\begin{abstract}
Road lighting causes unwanted ecological impact on species and habitats where species may be protected and/or light-sensitive. Yet, there is very little information available on how road lighting should be ecologically designed while simultaneously considering energy efficiency and the regulations needed for safety reasons. The aim of this study was study designs of different dimensions regarding energy efficiency, ecological impact and the compliance with regulations for traffic safety. By using DIALux evo simulations with four different LED luminaires, different scenarios of road lighting designs (pole distance of $10 \mathrm{~m}, 25 \mathrm{~m}$ and $40 \mathrm{~m}$, and pole heights of $3 \mathrm{~m}$, $5 \mathrm{~m}$, and $8 \mathrm{~m}$ ) on a $7 \mathrm{~m}$ wide road was evaluated. Ecological thresholds of 1 lux and 0.1 lux are possible to get below at distances from the road edge between $5-11 \mathrm{~m}$, and $8.5-20 \mathrm{~m}$, respectively. Results are discussed from the perspectives of increased demand on energy efficiency on road lighting.
\end{abstract}

Keywords: luminance, uniformity, TI, DIALux evo, pole height, pole distance

\section{Introduction}

Road lighting and outdoor lighting often have a high energy consumption owing to the long operating hours and requirements of luminance levels needed for fulfilling the regulations for traffic safety. Light emitting diodes (LED) is now widely applied as road lighting and can offer energy-efficient and environmentally friendly solutions when used correctly, while still fulfilling the traffic safety requirements. However, considering LED lighting from a sustainable and ecological perspective, the use of outdoor lighting can cause unwanted light pollution, ecological impact and environmental degradation (Jägerbrand, 2015, Jägerbrand, 2018).

Such unwanted impact will be especially harmful for endangered and protected species such as those protected by international and national legislations to ensure the conservation of protected species. For example, in Europe, the EU Birds and Habitats Directives (EEC, 1992, EC, 2009) aim to ensure the conservation of threatened and endangered species and habitats across the EU member states.

When species that are sensitive to artificial light will be exposed in their natural environment, their survival or foraging might be affected in a detrimental way, which is not approved by the legislation. Such ecological impact must be minimised by measures and reduced to levels that will not have a negative impact on species survival and well-being.

In general, recommendations for minimizing ecological impact are divided into five areas: prevent and limit new areas to illuminate, limit the range of illuminated areas, limit the time of illumination, limit the illuminance/light quantity, and adjustments in the light wavelength distribution (e.g. Gaston et al., 2012, Gaston et al., 2013, Dick, 2014)

Yet, light designers and environmental officials have very little information available on how road lighting should be designed and still fulfil the regulations needed for safety reasons while being the most energy efficient solution.

Since many organism and species perceive light in different ways, it is difficult to predict ecological impacts of artificial light. For example, some species are sensitive for red light such as nocturnally migrating birds, while others are less sensitive to red light compared to white 
light, such as bats (Jägerbrand, 2018). The ecological thresholds for when detrimental impact will cease on species have received very little attention, leading both light designers and ecologists to a lack knowledge of how ecological friendly road lighting should be designed. This leads to suboptimal and costly solutions without any evidence of reduced ecological impact.

Consequently, the aim of this study was to analyse the lighting design of road lighting and compare designs of different dimensions regarding energy efficiency, ecological impact (as thresholds) and the compliance with regulations for traffic safety.

\section{Materials and methods}

By using dialux simulations (in DIALux evo 7.1), several scenarios of road lighting designs were tested and evaluated from the three perspectives of energy efficiency, ecological impact and compliance of regulations for road lighting. The road had a width of $7 \mathrm{~m}$ and was surrounded by green lanes $40 \mathrm{~m}$ into the surrounding (Figure 1). The burning hours per year was set to 4000 . Four different luminaries between $27.5-82 \mathrm{~W}, 3000-4000 \mathrm{~K}$ and luminous efficacy between 111$126 \mathrm{Im} / \mathrm{W}$ were used for the same dimension of road (Table 1). The luminaire pole distance varied between $10 \mathrm{~m}, 25 \mathrm{~m}$, and $40 \mathrm{~m}$, and the pole height varied between $3 \mathrm{~m}, 5 \mathrm{~m}$, and $8 \mathrm{~m}$. Distance between road edge and the luminaire pole was below $1 \mathrm{~m}$.
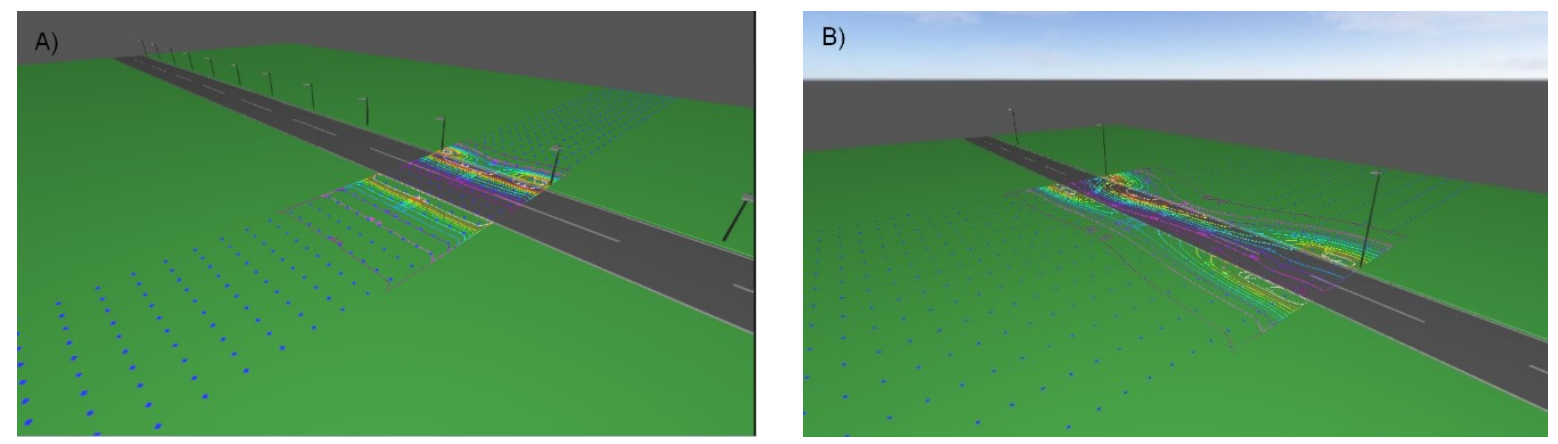

Figure 1 - Examples of simulations in DIALux evo 7.1. A) Dyana $55 \mathrm{~W} 10 \mathrm{~m}$ pole distance and $3 \mathrm{~m}$ pole height, B) Dyana $55 \mathrm{~W} 40 \mathrm{~m}$ pole distance and $8 \mathrm{~m}$ pole height.

Table 1 - Details of luminaire, power, color temperature and luminous efficacy.

\begin{tabular}{|l|l|l|l|}
\hline Luminaire & Power (W) & CCT (K) & Luminous efficacy (Im/W) \\
\hline Dyana LED & 55 & 4000 & 119 \\
\hline Evolume (LED) & 82 & 4000 & 125.6 \\
\hline ClearWay gen2 (LED) & 27.5 & 3000 & 111.4 \\
\hline Indico (LED) & 60 & 4000 & 112 \\
\hline
\end{tabular}

The compliance of regulations was analysed by the computed average road surface luminance (L), longitudinal uniformity (Uo) and threshold increment (TI). Energy efficiency was analysed by the power density indicator $\left(D_{P}\right)$, and the $A E C l$ (annual energy consumption indicator) (CEN $2016 \mathrm{a})$ and by luminaire power per kilometre $(\mathrm{W} / \mathrm{km})$. The ecological impact was analysed by ecological thresholds for horizontal illuminance at distances from the road lighting installation (mean values from backlight and frontlight).

The ecological thresholds used in this study was 1 lux and 0.1 lux. Threshold levels were chosen since many circadian species seems to be less sensitive to illuminance levels below 1-10 lux compared with higher illuminance levels (Jägerbrand, 2018). In addition, average illuminance of 1-3 lux on the ground and less than 3 lux at the eye is generally recommended to keep illuminance values at the lowest possible in sensitive areas to mitigate ecological impact in natural environments and to reduce light pollution (Dick, 2012). The Low Impact Lighting (LIL) 
standard states that the illumination on parking places on highways and roads must be kept under 1 lux (Licht und natur, n.a.). It therefore seems reasonable that illumination levels below 1 lux can be used as an ecological threshold for reducing unwanted ecological impact on circadian species and used as a precautionary principle for reducing possible impact on protected species.

The ecological threshold of 0.1 lux was chosen based on the assumption that moonlight may affect sensitive species. Supermoon (extreme case) may yield illuminance levels around $0.26-$ 0.3 lux (Kyba et al., 2017), and full moon 0.1-0.3 lux (Rich and Longcore, 2006), while 0.010.03 lux have been observed for quarter moon under clear sky (Rich and Longcore, 2006). Thus, a threshold level of 0.1 lux seems reasonable since full moon may have such illuminance levels but quarter moon may have lower illuminances, in general.

Circadian species may still be affected by illuminance levels of 0.1 but not all species have a well-developed scotopic vision to be able to perceive light at these low levels. The ecological impact on species of 0.1 lux (and below that) in terms of physiology and behavior is unknown (Kyba et al., 2017) but will depend on the species and the spectral power distribution of the light source. However, even if some of the nocturnal species may have tapetum lucidum to increase visual perception (a layer of tissue in the eye that increases visual perception), the visibility in 0.1 lux may still be low enough to avoid ecological impact. The ecological threshold of 0.1 lux was used in this study since it allows generalizations and comparisons of the light distribution into the surrounding environment at levels comparable to moon light.

\section{Results and discussion}

\subsection{Energy efficiency}

Results of the energy efficiency calculations show that the lowest power demand per kilometre road was found for the lighting designs with the largest pole distances, while the variation was not very large for $D_{P}$ (Table 2). Similarly, the highest values of $A E C I$ was found at shorter pole distances (Table 2). Values of AECI seems to be low compared with the typical values between 0.6-3.8 for LED on various types of roads (CEN, 2016b). However, power demand per kilometre road is similar to previous studies of LED road lighting, varying between $937-2833 \mathrm{~W} / \mathrm{km}$ (Jägerbrand, 2016).

Table 2 - Energy efficiency and pole distance. $D_{\mathrm{p}}$ in $\mathrm{W} \mathrm{Ix}^{-2} \mathrm{~m}^{-2}, \mathrm{AECl}$ in $\mathrm{kWh} \mathrm{m}^{-2}$ per year.

\begin{tabular}{|l|l|l|l|l|l|l|l|l|l|l|l|l|l|}
\hline Power & \multicolumn{3}{|c|}{$55 \mathrm{~W}$} & \multicolumn{3}{c|}{$82 \mathrm{~W}$} & \multicolumn{3}{c|}{$27.5 \mathrm{~W}$} & \multicolumn{3}{c|}{$60 \mathrm{~W}$} \\
\hline $\begin{array}{l}\text { Pole } \\
\text { distance } \\
(\mathrm{m})\end{array}$ & 10 & 25 & 40 & 10 & 25 & 40 & 10 & 25 & 40 & 10 & 25 & 40 \\
\hline $\mathrm{DP}$ & 0.013 & 0.013 & 0.013 & 0.012 & 0.012 & 0.012 & 0.013 & 0.013 & 0.013 & 0.013 & 0.013 & 0.013 \\
\hline $\mathrm{AECl}$ & 0.3 & 0.1 & 0.1 & 0.4 & 0.2 & 0.1 & 0.1 & 0.1 & 0 & 0.3 & 0.1 & 0.1 \\
\hline $\mathrm{W} / \mathrm{Km}$ & 5500 & 2200 & 1375 & 8200 & 3280 & 2050 & 2750 & 1100 & 687.5 & 6000 & 2400 & 1500 \\
\hline
\end{tabular}

\subsection{Compliance of regulations for road lighting}

Average mean road surface luminance $(L)$ was $1.15 \mathrm{~cd} / \mathrm{m}^{2}$ (S.E. 0.13) and was generally higher for the shortest pole distance and the shorter pole heights (Figure 2A). Only the shortest pole heights with $10 \mathrm{~m}$ pole distances fulfilled the requirements for $\mathrm{M} 1$, while all lighting designs with $10 \mathrm{~m}$ pole distances fulfilled $\mathrm{M} 2$ and $\mathrm{M} 3$, and $3 \mathrm{~m}$ and $5 \mathrm{~m}$, pole heights fulfilled $\mathrm{M} 3$ with $25 \mathrm{~m}$ pole distances (CEN, 2016a, and Appendix Table A1). Pole distances of 40m had L=0.55 (mean value, all pole heights) and were therefore able to fulfil M5 and M6 classes. Values of $L$ was in the same interval as has been reported previously for roads with LED road lighting (Jägerbrand, 2016).

Luminance uniformity (Uo) followed the opposite trend and was below 0.4 for most cases except for the $8 \mathrm{~m}$ pole heights (Figure 2B). Mean values of Uo were 0.27 (S.E. 0.04). For M classes of road lighting, the luminance uniformity must be $0.35-0.4$ to fulfil the requirements (CEN, 2016a, and Appendix Table A1). This was only the case for $8 \mathrm{~m}$ pole height (M1-M6) and $5 \mathrm{~m}$ pole height 
for $10 \mathrm{~m}$ pole distance (M5-M6) (Figure 2B). Uniformity was generally lower than reported previously from measurements in installations in the field (Jägerbrand, 2018). In that study levels of Uo below 0.4 and 0.35 was mainly only observed for pedestrian and bicyle roads. This might indicate that the luminaires used in the simulations had too low power demand to be used in reality if requirements of Uo must be fulfilled. However, the CEN standard is often not mandatory to use (for example for municipalities) so it is unsure to what extent the requirements for Uo is fulfilled, generally.

The mean threshold increment was $24 \%$ (S.E. 3.7) for all designs. Requirements for the threshold increments was not fulfilled for most designs since they resulted in $\mathrm{TI}$ above $20 \%$ (Figure 2C). Pole heights of $3 \mathrm{~m}$ resulted in too high TI for the requirements (CEN, 2016a, and Appendix Table A1), while pole heights of $5 \mathrm{~m}$ resulted in too high values when pole distances were $25 \mathrm{~m}$ or $40 \mathrm{~m}$ (Figure $2 \mathrm{C}$ ). Regarding the CEN standard, only $8 \mathrm{~m}$ pole heights and $5 \mathrm{~m}$ height with pole distance of $10 \mathrm{~m}$ were able to fulfil $\mathrm{TI} \leq 20 \%$ and $15 \%$.

A. Average road surface luminance

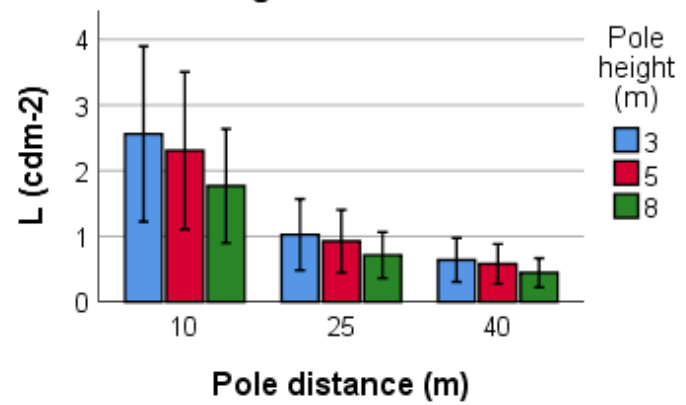

C. Threshold increment

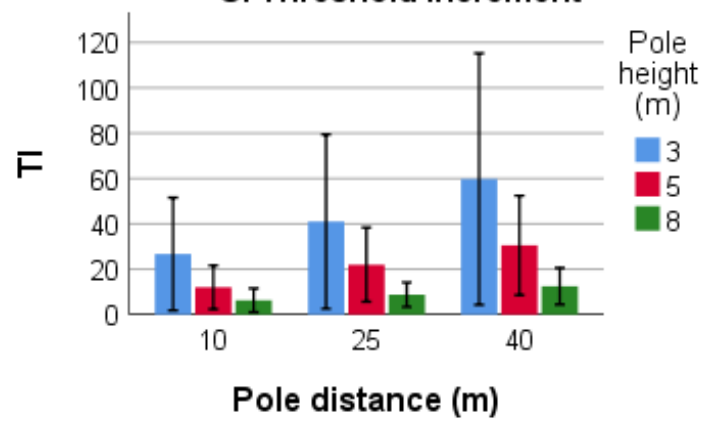

B. Luminance uniformity

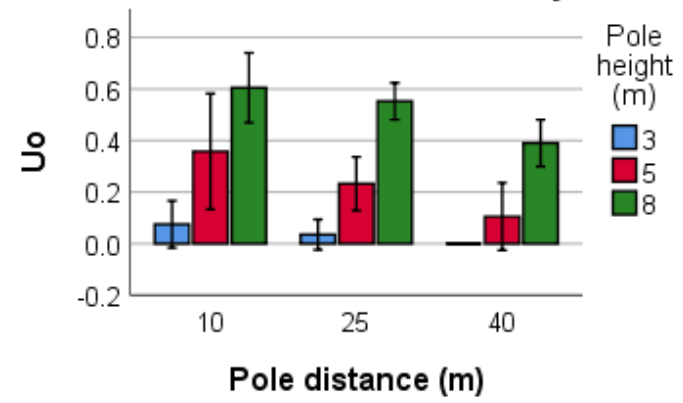

Figure 2 - Results of compliance with regulations, pole distance, and pole height. A) Average road surface luminance $(\mathrm{L})\left(\mathrm{cd} / \mathrm{m}^{2}\right)$, pole distance and height, B) overall luminance uniformity, pole distance and height, $\mathrm{C}$ ) threshold increment (TI) (\%), pole distance and height.

\subsection{Ecological thresholds}

Pole height seems to be a better predictor than pole distance for how many meters is needed into the surrounding environment to get below the ecological thresholds of 1 lux and 0.1 lux (Figure 3A-D). In general, the ecological threshold below 1 lux is obtained at $4.4 \mathrm{~m}, 6.8 \mathrm{~m}$, and $10.6 \mathrm{~m}$ for pole heights of $3 \mathrm{~m}, 5 \mathrm{~m}$, and $8 \mathrm{~m}$, respectively (Figure $3 \mathrm{~B}$ ). Similarly, distances of $8.5 \mathrm{~m}, 13.5 \mathrm{~m}$, and $20 \mathrm{~m}$ results in thresholds below 0.1 lux for pole heights of $3 \mathrm{~m}, 5 \mathrm{~m}$, and $8 \mathrm{~m}$, respectively (Figure 3D). The results indicate that decreased ecological impact can be achieved by reducing pole heights in combination with optimal pole distance.

Thresholds of 1 lux and 0.1 lux are possible to get below at distances between $5-11 \mathrm{~m}$ and $8.5-$ $20 \mathrm{~m}$, respectively, when the road lighting is designed within the limits used in this study $(3-8 \mathrm{~m}$ pole heights and $10-40 \mathrm{~m}$ pole distances). However, calculations of the distances were made based on mean values of the frontlight and backlight from the road edge, which means that actual values of threshold distances may have larger variation than shown in the figures. The difference in distances may be large because it also depends on the width of the road for singlesided installations. For two-sided installations, the threshold distances will be more uneven in the surrounding and increase the area affected by higher illuminance levels. It is therefore 
recommended to use single-sided installations, especially in sensitive or protected areas (Jägerbrand, 2018).

For average road surface luminance, the relationship between height, distance and distance of the ecological threshold is not completely clear, while the pole distance of $10 \mathrm{~m}$ result in luminance values above $1.5-2 \mathrm{~cd} / \mathrm{m}^{2}$ (Figure $3 \mathrm{~A}$ ). Increased ecological distances are shown in pole heights of $8 \mathrm{~m}$ (Figure 3B \& 3D).

A. Luminance and ecological treshold of 1 lux

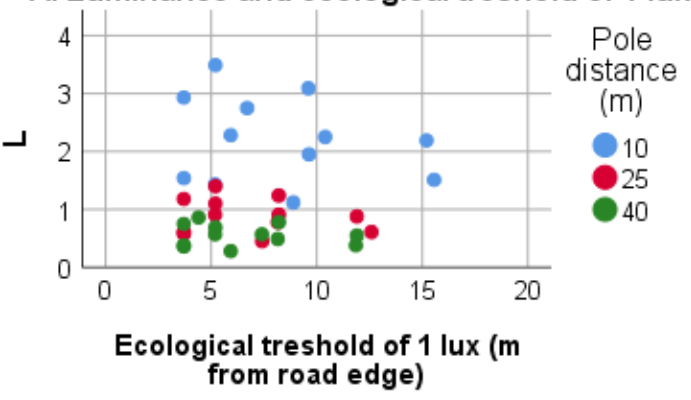

C. Luminance and ecological threshold of 0.1 lux

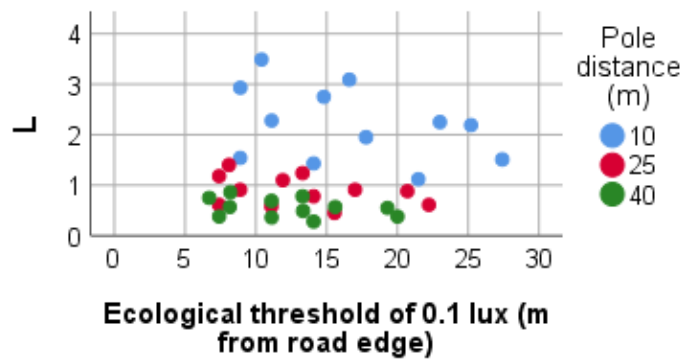

B. Luminance and ecological threshold of 1 lux

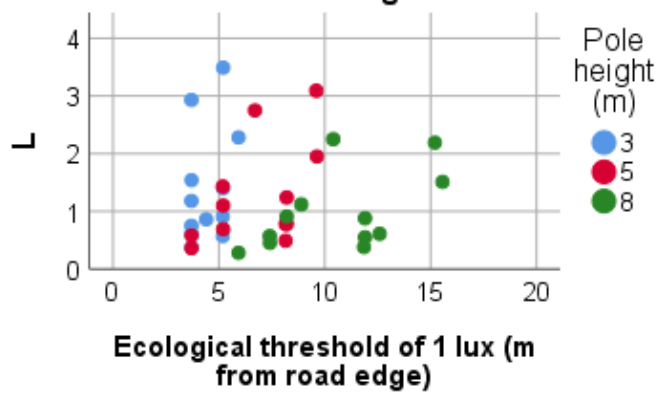

D. Luminance and ecological threshold of 0.1 lux

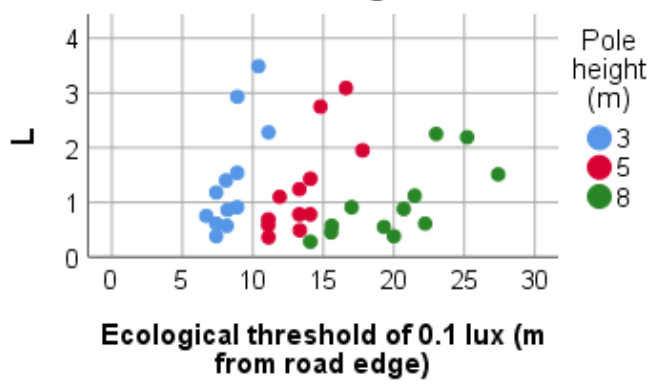

Figure 3 - Average road surface luminance $(\mathrm{L})\left(\mathrm{cd} / \mathrm{m}^{2}\right)$ and ecological thresholds. A) luminance and ecological threshold distances of 1 lux for different pole distances, B) luminance and ecological threshold distances of 1 lux for different pole heights, C) luminance and ecological threshold distances of 0.1 lux for different pole distances, and D) luminance and ecological threshold distances of 0.1 lux for different pole heights.

There is a linear relationship between pole distance/height, and the overall luminance uniformity (Uo) (Figure 4A-D).

In general, shorter pole heights results in shorter distances of ecological thresholds. For example, pole heights of $3 \mathrm{~m}$ results in ecological thresholds distances of below $10 \mathrm{~m}$ for 1 lux and below $12.5 \mathrm{~m}$ for 0.1 lux (Figure 4B \& 4D). Such short distances may be realistic to a chieve in sensitive environments where light sensitive species occur since it is important then high priority to reduce the intrusion of artificial light into the environment.

If the requirements of Uo must be fulfilled only the pole heights of $8 \mathrm{~m}$ and $5 \mathrm{~m}$ is realistic to use. Unfortunately, the pole heights of $8 \mathrm{~m}$ causes very long distances for the ecological thresholds. For example, between $6 \mathrm{~m}$ to $16 \mathrm{~m}$ for 1 lux and ca $15 \mathrm{~m}$ to $27 \mathrm{~m}$ for 0.1 lux (Figure 4B \& 4D).

It seems that the most optimal design regarding Uo and ecological thresholds is achieved with $5-8 \mathrm{~m}$ pole heights and when the pole distance can be further adapted to increase the Uo without causing increased distances for the ecological thresholds. 

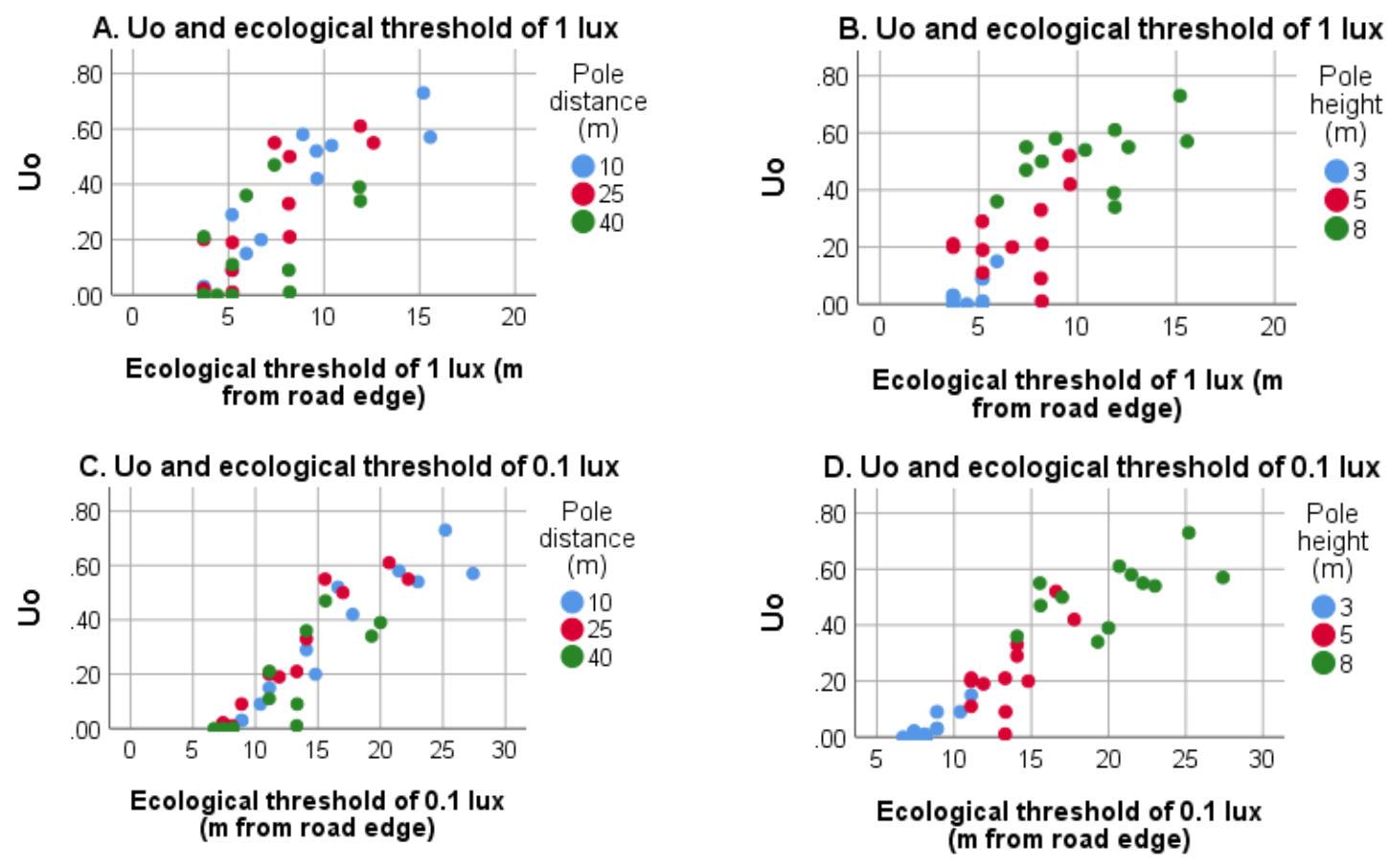

Figure 4 - Overall luminance uniformity (Uo) and and ecological thresholds. A) Uo and ecological threshold distances of 1 lux for different pole distances, B) Uo and ecological threshold distances of 1 lux for different pole heights, C) Uo and ecological threshold distances of 0.1 lux for different pole distances, and D) Uo and ecological threshold distances of 0.1 lux for different pole heights.

The threshold increment ( $\mathrm{TI})$ shows an inverse relationship with the ecological threshold distances (Figure 5A-D). For most cases, the limit of maximum $20 \% \mathrm{TI}$ is not achieved. For pole heights of $5 \mathrm{~m}$ and $8 \mathrm{~m}$ the $\mathrm{TI}$ is fulfilled in accordance with the standard (CEN, 2016a), but the distance of an ecological threshold below 1 lux exhibits high variation (from $6 \mathrm{~m}$ to $16 \mathrm{~m}$ ) (Figure 5B). Similarly, pole heights of $8 \mathrm{~m}$ results in long distances for the ecological thresholds between ca $14 \mathrm{~m}$ to $27 \mathrm{~m}$ (Figure 5D). 

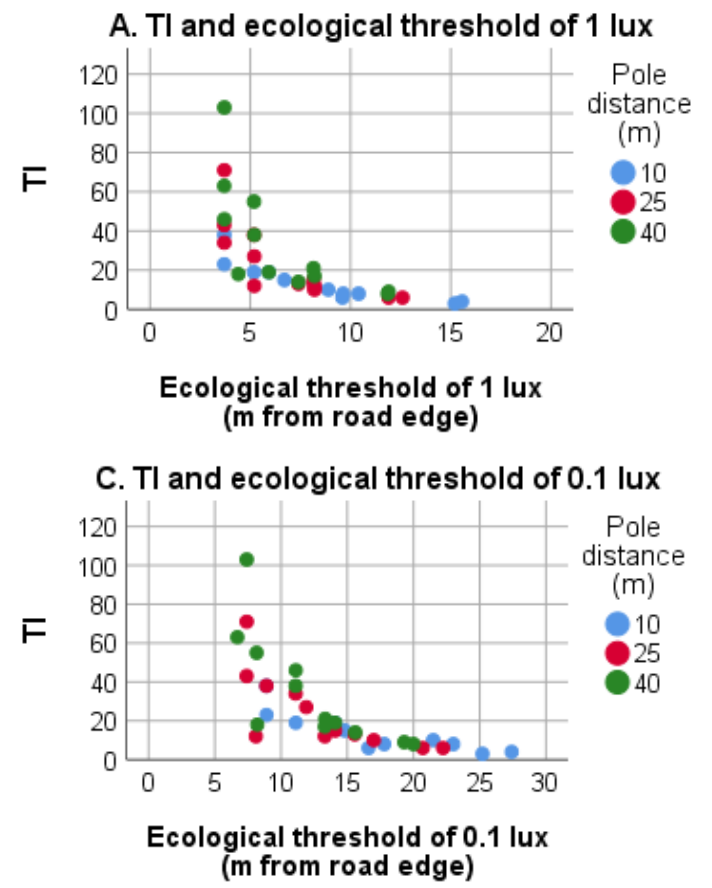

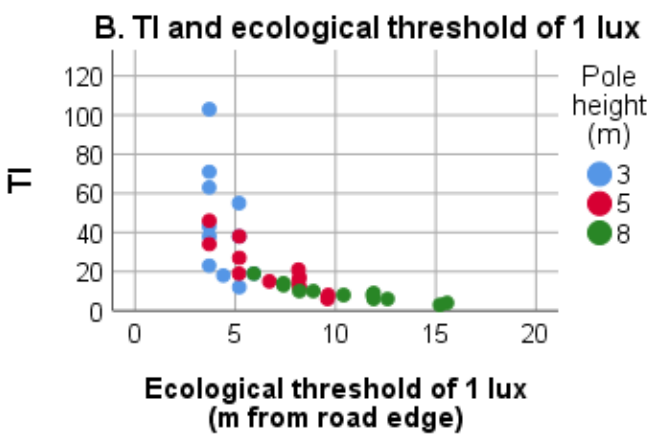

D. TI and ecological threshold of 0.1 lux

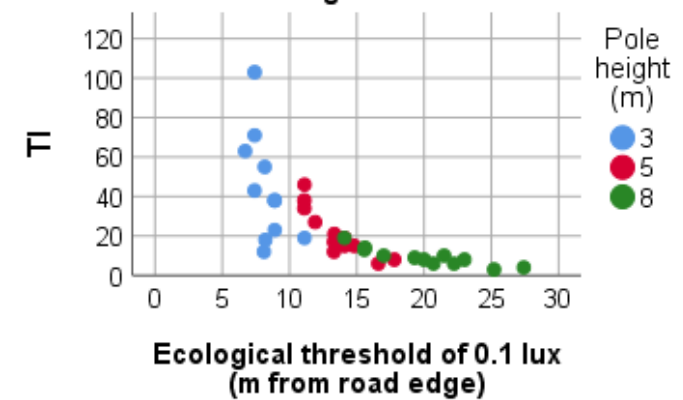

Figure 5 - Threshold increment (TI) (\%) and and ecological thresholds. A) TI and ecological threshold distances of 1 lux for different pole distances, B) TI and ecological threshold distances of 1 lux for different pole heights, C) TI and ecological threshold distances of 0.1 lux for different pole distances, and D) $\mathrm{TI}$ and ecological threshold distances of 0.1 lux for different pole heights.

\section{Conclusions}

In general, higher light poles result in higher energy efficiency, overall luminance uniformity and lower threshold increment, but will result in longer distances to reach below the ecological thresholds.

The relationships between average road surface luminance and distances of the ecological thresholds shows that the requirements for fulfilling the road lighting $M$ classes is associated with pole heights of $8 \mathrm{~m}$, but due to the variation from pole distance, higher pole heights do not necessary result in increased distances in ecological thresholds. It seems that it is possible to balance between optimal average road surface luminance and distance for ecological threshold through adaptations in the lighting design (adjustments between height and distance).

Increases towards higher energy efficiency (to save money and energy), and the requirements stated by the standards such as CEN (European Committee for Standardisation) for overall luminance uniformity and threshold increment put more pressure on the use of higher light poles. Unfortunately, the use of higher light poles will increase the distance to get below the ecological thresholds, resulting in more artificial light penetrating the surroundings.

Future studies include more detailed analyses since it seems that for the settings used in this study ( $7 \mathrm{~m}$ wide road), the most optimal and balanced lighting solution might be found at pole heights below $8 \mathrm{~m}$ but above $5 \mathrm{~m}$.

The most optimal "ecological" lighting design should be able to achieve low energy consumption, fulfil the requirements and result in relatively short distances to reach below the ecological thresholds. 


\section{Acknowledgements}

This work was supported by the Department of Construction Engineering and Lighting Science (School of Engineering) at Jönköping University, Calluna $A B$, and Bertil \& Britt Svenssons stiftelse för belysningsteknik. They are gratefully acknowledged.

\section{Appendix}

Appendix Table A1 - M road lighting classes, average road surface luminance (L), overall uniformity (Uo) and threshold increment (TI) (of an object at the road surface). Dry conditions. Adapted from (CEN, 2016a).

\begin{tabular}{|l|l|l|l|}
\hline Class & L (minimum maintained) & Uo (minimum) & TI (maximum) \% \\
\hline M1 & 2.0 & 0.40 & 10 \\
\hline M2 & 1.5 & 0.40 & 10 \\
\hline M3 & 1.0 & 0.40 & 15 \\
\hline M4 & 0.75 & 0.40 & 15 \\
\hline M5 & 0.5 & 0.35 & 15 \\
\hline M6 & 0.3 & 0.35 & 20 \\
\hline
\end{tabular}

\section{References}

CEN 2016a. Road lighting - Part 2: Performance requirements, EN 13201-2. European Committee for Standardisation (CEN), Brussels: European Standard.

CEN 2016b. Road lighting - Part 5: Energy performance indicators, EN 13201-5. European Committee for Standardisation (CEN), Brussels: European Standard.

DICK, R. 2012. Scotobiology. Special Issue "Environmental impact of light pollution and its abatement" Special Report of the Journal of the Royal Astronomical Society of Canada, 710.

DICK, R. 2014. Applied scotobiology in luminaire design. Lighting Research \& Technology, 46, $50-66$.

EC. 2009. Directive 2009/147/EC of the European parliament and of the council of 30 November 2009 on the conservation of wild birds. European Commission. Official Journal of the European Union.

EEC. 1992. Council Directive $92 / 43$ /EEC of 21 May 1992 on the conservation of natural habitats and of wild fauna and flora. European Economic Community. Official Journal of the European Communities.

GASTON, K. J., BENNIE, J., DAVIES, T. W. \& HOPKINS, J. 2013. The ecological impacts of nighttime light pollution: A mechanistic appraisal. Biological Reviews, 88, 912-927.

GASTON, K. J., DAVIES, T. W., BENNIE, J. \& HOPKINS, J. 2012. Reducing the ecological consequences of night-time light pollution: Options and developments. Journal of Applied Ecology, 49, 1256-1266.

JÄGERBRAND, A. K. 2015. New framework of sustainable indicators for outdoor LED (light emitting diodes) lighting and SSL (solid state lighting). Sustainability, 7, 1028-1063.

JÄGERBRAND, A. K. 2016. LED (Light-Emitting Diode) road lighting in practice: An evaluation of compliance with regulations and improvements for further energy savings. Energies, 9, 357.

JÄGERBRAND, A. K. 2018. LED-belysningens effekter på djur och natur med rekommendationer: Fokus på nordiska förhållanden och känsliga arter och grupper. Calluna AB. 
KYBA, C., MOHAR, A. \& POSCH, T. 2017. How bright is moonlight? A\&G Astronomy and Geophysics, 58, 1.31-1.32.

LICHT UND NATUR. n.a. Standards of Low Impact Lighting (LIL) [Online]. Licht und natur, light pollution experts coalition (Germany, Italy, Slovenia). Available: https://www.licht-undnatur.eu/lpec-in-eeb/standards-of-low-impact-lighting/ [Accessed 20 March 2019].

RICH, C. \& LONGCORE, T. 2006. Ecological Consequences of Artificial Night Lighting. Washington, Covelo, London: Island Press. 